\title{
FREE VIBRATION ANALYSIS OF MULTI-SPAN ORTHOTROPIC BRIDGE DECK WITH RUBBER BEARINGS
}

\author{
Imed FARAH ${ }^{1}$, Abdelouahab REZAIGUIA ${ }^{2}$, Ahcene MOUASSA ${ }^{3}$, Laefer DEBRA ${ }^{4}$, \\ Salah GUENFOUD ${ }^{5}$ \\ ${ }^{1,2,5}$ Applied Mechanics of New Materials Laboratory, University of 8 May 1945-Guelma, Algeria \\ ${ }^{3}$ Mechanic and Structures Laboratory, University of 8 May 1945-Guelma, Algeria \\ ${ }^{1}$ imedf3000s@gmail.com, ${ }^{2}$ a.rezaiguia@gmail.com, ${ }^{2}$ rezaiguia.abdelouahab@ univ-guelma.dz, ${ }^{3}$ amouas- \\ sa@yahoo.fr, ${ }^{5}$ strucmec@gmail.com \\ ${ }^{4}$ Center for Urban Science and Progress and Department of Civil Engineering, Tandon School of Engineering \\ Center for Urban Science and Progress, New York University, United States of America \\ 르라.laefer@nyu.eud
}

\begin{abstract}
In this paper, a semi-analytical approach is proposed for free vibration analysis of a multi-span, orthotropic bridge deck with rubber bearings. This allows more realistic modeling of vibration transmission from a bridge's deck to its supports. The approach is based on modal superposition incorporating intermodal coupling. The bridge deck was modeled as a continuous, multi-span, orthotropic rectangular plate with equivalent rigidities. The rubber bearings were inserted between the girders and rigid supports to absorb traffic induced vibrations. The rubber bearing was modeled by linear elastic, vertical supports as very flexible in rotation and highly rigid in the vertical direction. The method's efficacy was validated against two numerical examples. The absolute error was less than $10 \%$.
\end{abstract}

Keywords: free vibration; multi-span orthotropic bridge deck; rubber bearing; elastic support; intermodal coupling

\section{INTRODUCTION}

Understanding free vibrations of multi-span roadway bridge decks is an essential step in studying the forced vibrations under traffic loading. To date, several types of bridge deck sections have been accurately homogenized as orthotropic plates with equivalent rigidities [1,2]. Prominent amongst these are the early contributions by Timoshenko and Woinowsky [3] and Leissa [4] on continuous rectangular plates, plates on elastic foundations, and the bending of anisotropic plates. More recently, Zhu and Law [5] modeled a moving load on a multi-span, continuous Euler-Bernoulli beam with elastic bearings. In that work, each bearing was modeled with vertical and rotational stiffness. To quantify the moving load, a method based on modal superposition was combined with a regularization technique using different types of measured responses. The authors concluded that vertical support stiffness strongly influenced the identified loads when the beam's flexural stiffness was small. Lin and Chang [6] adopted a hybrid analytical/numerical method to study the free vibration of a continuous, multi-span, Timoshenko beam, simply supported at its ends with intermediate flexible supports. In that work, two sets of equations of motion were written for each segment: one for the vertical displacement and one for the slope. The application of the boundary and compatibility con- ditions yielded the characteristic polynomial which was not increased in degrees, despite the larger number of intermediate supports. In not unrelated work, Li et al. [7] developed an analytical method to determine natural frequencies and mode shapes of a rectangular single-span, isotropic thin plate with all edges having uniform elastic supports (i.e. elastically restrained). In that, the vertical displacement of the plate was expressed as a combination of several Fourier series expansions, which satisfied both the equation of motion and the boundary conditions at all edges. This general method is applicable to a variety of classical cases, as demonstrated by the strong agreement with previously published finite element modeling (Takabatake and Nagareda [8]). Li et al. [7] claimed that that method could be extended to non-uniform, restrained points, partial supports, and combinations of those. In the previously referenced work of Takabatake and Nagareda [8], those authors developed a simplified, analytical method to analyze static, free, and forced vibrations of a thin, isotropic, rectangular plate with edge beams. The boundary conditions of the plate were supported with edge beams (as previously solved by Vinson [9]) and then replaced with edges elastically restrained against translation and rotation. Takabatake and Nagreda [8] used the Galerkin method for static analysis of the plate. Good agreement was seen, when the closed form approximation was compared 
to a FEM model. Cheung and Zhou [10] also investigated free vibrations of orthotropic, thin, rectangular plates with intermediate, elastic, line-supports in two directions and with edge constraints. That study was based on static beam functions along the $x$ - and $y$-directions in the Rayleigh-Ritz method. Notably their decomposition of mode shapes did not incorporate the intermodal coupling caused by the mixed derivatives that appear in the formulation of free edge plate conditions [11]. In affiliated work, a semi-analytical approach to determine natural frequencies and mode shapes of an orthotropic, multispan plate with rigid line supports was introduced by Rezaiguia and Laefer [12] and Rezaiguia et al. [13] based on modal superposition and the inclusion of intermodal coupling. When compared to FEM models, the mode shapes matched, and the frequencies were within $2 \%$, despite the approach's comparative simplicity, thereby making it a good candidate to study the dynamic interaction between bridge decks and vehicles. In commercial bridge design, rubber supports are modelled as a two-joint link aligned vertically, in such a way that one end is connected to the bridge deck and the other end is fixed as per Kunde and Jangid [14].

The following research extends modal superposition with the intermodal coupling approach $[12,13]$ through the inclusion of elastic, line supports. Specifically, the vertical displacement of the plate is obtained by modal superposition. The mode shapes are decoupled, as the product of two admissible functions. In the longitudinal direction, natural frequencies and mode shapes are obtained using boundary and continuity conditions. In the transversal direction, the mode shapes of the plate are presented with a function satisfying exact boundary conditions of the free plate to take into account the intermodal coupling.

\section{MATHEMATICAL MODELING}

During the construction of the roadway bridges, an elastomeric restraining device, called rubber bearing, is inserted between the girders and the rigid supports to bring more flexibility to the structure. (Fig. 1). When a slab rests on rubber bearings, the bearing provides most of the structure's flexibility. Thus, incorporating them into the dynamic model is critical for correctly calculating the natural periods. The bearing has the capability of absorbing applied forces vertically and horizontally and is very effective in reducing the structure's response to seismic loading by reducing natural frequencies. This is done by providing more flexibility to the slab and extending the condition of the head of the piles longer than would otherwise be possible. In addition, in case of damage or deterioration should occur, the rubber bearing is relatively easy to change.
In the vast majority of cases, the rubber bearing can be considered as highly rigid in the vertical direction and very flexible in rotation [15]. The bearing has the capability of absorbing vertically and horizontally applied forces and is very effective in reducing the structure's response to seismic loading. Consequently, its inclusion in a mathematical model is needed for generating realistic responses. Specifically, rubber can be modeled by stiffness and damping. Stiffness must be considered in the free vibrations, because the natural frequencies and mode shapes without damping of the bridge deck are needed to calculate the forced vibration response. Damping of both the bridge deck and rubber bearing must be considered in the forced vibrations. The damping of the bridge deck and the rubber bearings are taken into account through the forced vibrations.

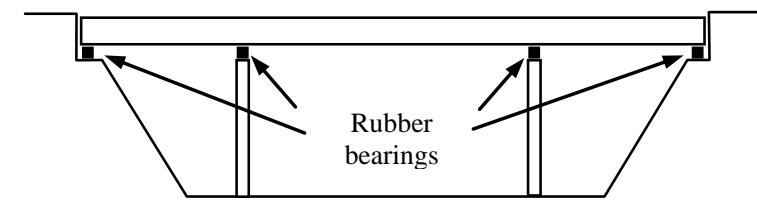

Fig. 1. Longitudinal section of a bridge with rubber bearings [15]

In this study, a bridge deck is modeled by a thin, orthotropic, rectangular plate of length $l$, width $b$, thickness $h$, and density $\rho$, supported by several elastic, line supports (Fig. 2). All supports are perpendicular to the free edges of the bridge deck. Free vibrations without damping of the bridge deck are governed by the following homogeneous differential eq.(1):

$$
\rho h \frac{\partial^{2} w}{\partial t^{2}}+D_{x} \frac{\partial^{4} w}{\partial x^{4}}+2 H \frac{\partial^{4} w}{\partial x^{2} \partial y^{2}}+D_{y} \frac{\partial^{4} w}{\partial y^{4}}=0
$$

In equation $(1), w(x, y, t)$ is the vertical displacement of the bridge deck, $D_{x}=E_{x} h^{3} / 12\left(1-v_{x y} v_{y x}\right)$ is the flexural rigidity in the $x$-direction,,$D_{y}=D_{x} E_{y} / E_{x}$ is the flexural rigidity in the $y$-direction, $\mathrm{H}=v_{x y} D_{y}+2 D_{x y}$ is the equivalent flexural rigidity, $v_{x y}$ and $v_{y x}$ are the Poisson's ratio in the $x$ - and $y$ directions, respectively, $D_{x y}=G_{x y} h^{3} / 12$ is the torsional rigidity, $G_{x y}$ is the shear modulus, and $E_{x}$ and $E_{y}$ are the Young's moduli in the $x$ - and $y$-directions, respectively. Using the modal superposition method, the vertical displacement of the bridge deck in free vibrations is written as eq.(2):

$$
w(x, y, t)=\sum_{i=1}^{n} \sum_{j=1}^{m} a_{i j} W_{i j}(x, y) e^{J \omega_{i j} t}
$$

where $\omega_{i j}$ and $W_{i j}(x, y)$ are the natural frequencies and mode shapes of the multi-span bridge deck with elastic supports, respectively, $a_{i j}$ are the modal amplitudes, and $J=\sqrt{-1}, n$ and $m$ are the mode numbers following $x$ and $y$, respectively [necessary for convergence of the modal series in eq. (2), 
which can be excited in practice]. Substituting eq. (2) into eq. (1) yields:

$$
\begin{aligned}
& \sum_{i=1}^{n} \sum_{j=1}^{m} a_{i j}\left[-\rho h \omega_{i j}^{2} W_{i j}+D_{x} \frac{\partial^{4} W_{i j}}{\partial x^{4}}+\right. \\
&\left.2 H \frac{\partial^{4} W_{i j}}{\partial x^{2} \partial y^{2}}+D_{y} \frac{\partial^{4} W_{i j}}{\partial y^{4}}\right] e^{J \omega_{i j} t}=0
\end{aligned}
$$

To determine the natural frequencies and mode shapes of the bridge deck, requires solving the following spatial differential eq. (4):
$D_{x} \frac{\partial^{4} W_{i j}}{\partial x^{4}}+2 H \frac{\partial^{4} W_{i j}}{\partial x^{2} \partial y^{2}}+D_{y} \frac{\partial^{4} W_{i j}}{\partial y^{4}}-\rho h \omega_{i j}^{2} W_{i j}=0$

To incorporate the intermodal coupling, the solution adopted herein for eq. (4) is that which was previously proposed $[12,13]$, where $W_{i j}(x, y)$ is expressed as the product of two admissible functions: $\varphi_{i}(x)$ are eigenfunctions of multi-span continuous beam with flexible supports, and $h_{i j}(y)$ are eigenfunctions of a single span beam satisfying the boundary conditions of a plate. This decomposition may be expressed as eq. (5).

$$
W_{i j}(x, y)=\varphi_{i}(x) h_{i j}(y)
$$

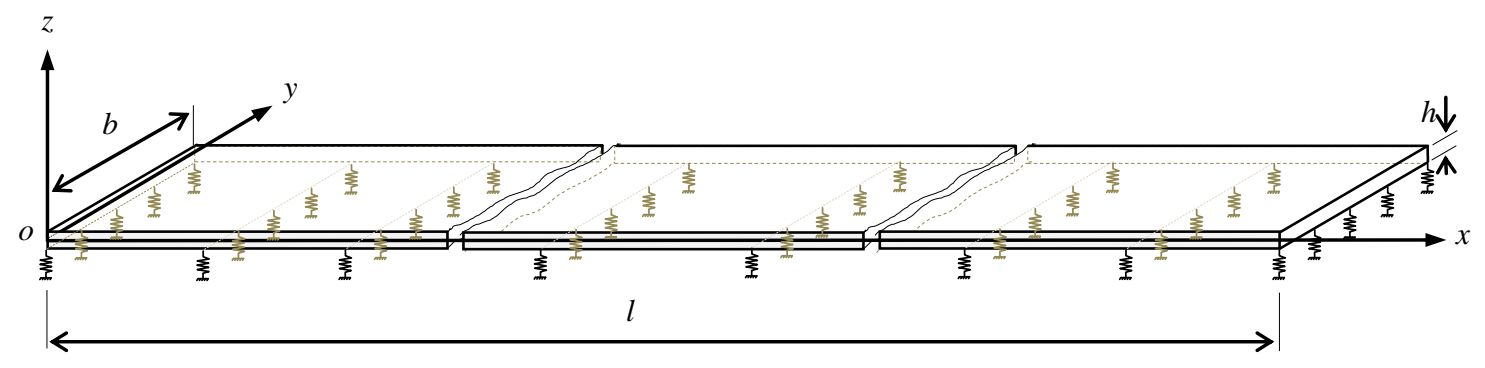

Fig. 2. Multi-span bridge deck with elastic linear supports

\subsection{Natural frequencies and mode shapes of a multi-span beam with elastic supports}

In the longitudinal direction $x$, the bridge deck is modelled by as an Euler-Bernoulli beam of length $l$, Young modulus $E_{x}$, mass per unit length $\rho A$, and moment of inertia $I$. The beam is divided into $R$-span of lengths $l_{l}, l_{2}, \ldots, l_{R}$, respectively (Fig. 3 ). The supports are modelled by linear springs of rigidities $k_{1}, k_{2}, \ldots, k_{R+1}$ respectively. To determine the mode shapes of a multi-span beam with elastic supports requires determining the mode shapes of each span by incorporating the boundary conditions and continuity conditions at intermediate supports. The expression of the $i^{\text {th }}$ mode shapes in the $r^{\text {th }}$ span is given by eq.(6) where the index $i$ is omitted for terms $\varphi_{r i}, A_{r i}, B_{r i}, C_{r i}, D_{r i}$ and $\lambda_{i}$ :

$$
\begin{aligned}
\varphi_{r}\left(x_{r}\right)=A_{r} \sin \lambda x_{r}+B_{r} \cos \lambda x_{r}+C_{r} \operatorname{sh} \lambda x_{r} & \\
+ & +D_{r} \operatorname{ch} \lambda x_{r} \quad r=1,2, \ldots, R
\end{aligned}
$$

$A_{r}, B_{r}, C_{r}$ and $D_{r}$ are constants to be determined by the application of boundary and continuity conditions, and $\lambda$ is a frequency parameter of the mul- ti-span beam. Zhu and Law [5] presented the formulation of the eigenfunctions and mode shapes of a multi-span, continuous beam with rotational and linear springs. In the study herein, the rotational spring is neglected, because the rubber bearing is very flexible in rotation [15].

At the left end of the beam, the shear force must equal the spring force that models the support, and the bending moment must be zero:

$$
\begin{gathered}
\left.E_{x} I \frac{d^{3} \varphi_{1}\left(x_{1}\right)}{d x_{1}^{3}}\right|_{x_{1}=0}=-\left.k_{1} \varphi_{1}\left(x_{1}\right)\right|_{x_{1}=0} \\
\left.E_{x} I \frac{d^{2} \varphi_{1}\left(x_{1}\right)}{d x_{1}^{2}}\right|_{x_{1}=0}=0
\end{gathered}
$$

At intermediate supports $r=2, \ldots, R$, the compatibility of shear forces and bending moments and the continuity of displacements and slopes are illustrated, respectively, by eq. (9-12):

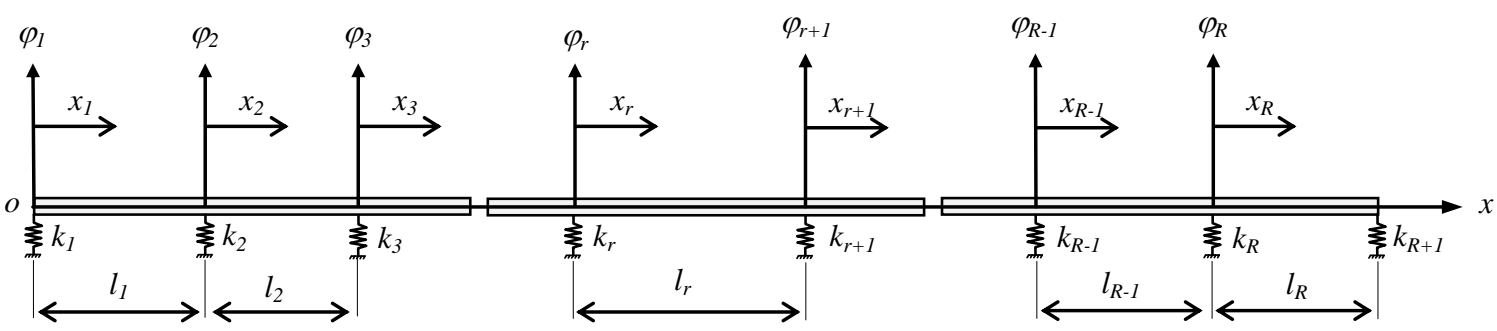

Fig. 3. Multi-span beam with elastic point supports 


$$
\begin{gathered}
\left.E_{x} I \frac{d^{3} \varphi_{r-1}\left(x_{r-1}\right)}{d x_{r-1}^{3}}\right|_{x_{r-1}=l_{r-1}}=\left.(-1)^{r} \quad k_{r} \varphi_{r-1}\left(x_{r-1}\right)\right|_{x_{r-1}=l_{r-1}} \\
\quad+\left.E_{x} I \frac{d^{3} \varphi_{r}\left(x_{r}\right)}{d x_{r}^{3}}\right|_{x_{r}=0} \\
\left.E_{x} I \frac{d^{2} \varphi_{r-1}\left(x_{r-1}\right)}{d x_{r-1}^{2}}\right|_{x_{r-1}=l_{r-1}}=\left.E_{x} I \frac{d^{2} \varphi_{r}\left(x_{r}\right)}{d x_{r}^{2}}\right|_{x_{r}=0} \\
\left.\varphi_{r-1}\left(x_{r-1}\right)\right|_{x_{r-1}=l_{r-1}}=\left.\varphi_{r}\left(x_{r}\right)\right|_{x_{r}=0} \\
\left.\frac{d \varphi_{r-1}\left(x_{r-1}\right)}{d x_{r-1}}\right|_{x_{r-1}=l_{r-1}}=\left.\frac{d \varphi_{r}\left(x_{r}\right)}{d x_{r}}\right|_{x_{r}=0}
\end{gathered}
$$

At the right end of the beam, the shear force must equal the force in the spring that models the support, and the bending moment must be zero:

$$
\begin{gathered}
\left.E_{x} I \frac{d^{3} \varphi_{R}\left(x_{R}\right)}{d x_{R}^{3}}\right|_{x_{R}=l_{R}}=\left.(-1)^{R+1} k_{R+1} \varphi_{R}\left(x_{R}\right)\right|_{x_{R}=l_{R}} \\
\left.E_{x} I \frac{d^{2} \varphi_{R}\left(x_{R}\right)}{d x_{R}^{2}}\right|_{x_{R}=l_{R}}=0
\end{gathered}
$$

After incorporating the conditions in eq. (7-14) into eq. (6), simplifying and regrouping, the system in eq. (15) is obtained:

$$
[F]\{A\}=\{0\}
$$

where the individual elements of the matrix $[\mathrm{F}]$ and vector $\{\mathrm{A}\}$ are presented in Appendix A.

\subsection{Natural frequencies and mode shapes of free-free orthotropic plate}

To incorporate the intermodal coupling, the mode shapes in the $y$-direction are presented as the function $h_{i j}(y)$, thus satisfying the boundary conditions of a plate at the free edges $y=0$ and $y=b$. Determination of the function $h_{i j}(y)$ is presented in detail elsewhere [i.e.12-13]. To clarify this for the reader, a summary of the approach in which the function $h_{i j}(y)$ is obtained is presented. Specifically, the differential eq. (4) must be satisfied for all values of $x$, but determining its resolution for every value of $x$ is practically impossible to achieve. For this reason, eq. (5) is substituted into eq. (4) and then multiplied by $\varphi_{i}(x)$ and integrated over the bridge length. From this, one obtains eq. (16):

$$
\begin{aligned}
D_{y} \frac{d^{4} h_{i j}}{d y^{4}} \int_{0}^{l} \varphi_{i}^{2} d x & +2 H \frac{d^{2} h_{i j}}{d y^{2}} \int_{0}^{l} \varphi_{i}^{\prime \prime} \varphi_{i} d x \\
& +\left(D_{x} \lambda_{i}^{4}-\rho h \omega_{i j}^{2}\right) h_{i j} \int_{0}^{l} \varphi_{i}^{2} d x=0
\end{aligned}
$$

Dividing eq. (16) by $D_{y} \int_{0}^{l} \varphi_{i}^{2} d x$, one obtains $\left(\varphi_{i}^{\prime \prime}=-\lambda_{i}^{2} \psi_{i}\right)$ :

$$
\frac{d^{4} h_{i j}}{d y^{4}}-\frac{2 H \lambda_{1 i}^{2}}{D_{y}} \frac{d^{2} h_{i j}}{d y^{2}}+\left(\left(D_{x} \lambda_{i}^{4}-\rho h \omega_{i j}^{2}\right) / D_{y}\right) h_{i j}=0
$$

with a new frequency parameter eq. (18):

$$
\lambda_{1 i}=\lambda_{i} \sqrt{\int_{0}^{l} \psi_{i} \varphi_{i} d x / \int_{0}^{l} \varphi_{i}^{2} d x}
$$

Hence, the solution of eq. (17) is given by the general form in eq. (19):

$$
h_{i j}(y)=A_{i j} e^{s_{i j} y}
$$

Substituting expression (19) into eq. (17), one obtains eq. (20):

$$
s_{i j}{ }^{4}-\frac{2 H \lambda_{1 i}^{2}}{D_{y}} s_{i j}^{2}+\left(\frac{D_{x} \lambda_{i}^{4}-\rho h \omega_{i j}^{2}}{D_{y}}\right)=0
$$

The roots of eq. (20) are eq. (21) and eq. (22):

$$
\begin{aligned}
& s_{1 i j}= \pm \frac{1}{\sqrt{D_{y}}} \sqrt{H k_{1 i}^{2}+\sqrt{H^{2} \lambda_{1 i}^{4}-D_{y}\left(D_{x} \lambda_{i}^{4}-\rho h \omega_{i j}^{2}\right)}}= \pm r_{1 i j} \\
& s_{2 i j}= \pm J \frac{1}{\sqrt{D_{y}}} \sqrt{H \lambda_{1 i}^{2}-\sqrt{H^{2} \lambda_{1 i}^{4}-D_{y}\left(D_{x} \lambda_{i}^{4}-\rho h \omega_{i j}^{2}\right)}}= \pm J r_{2 i j}
\end{aligned}
$$

Note that the parameters $r_{1 i j}$ and $r_{2 i j}$ are not independent but are instead, related by the pulsations $\omega_{i j}$. By substituting eq.s (21 and 22) into eq. (19) and replacing the exponential functions by trigonometric and hyperbolic functions, one obtains eq. (23):

$$
\begin{aligned}
h_{i j}(y)=C_{i j} \sin r_{2 i j} y+D_{i j} \cos r_{2 i j} y \\
+E_{i j} \sinh r_{1 i j} y+F_{i j} \cosh r_{1 i j} y
\end{aligned}
$$

where $C_{i j}, D_{i j}, E_{i j}$ and $F_{i j}$ are new constants of integration. They are determined by the application of the boundary conditions at the free edges of the bridge deck: $y=0$ and $y=b$. At these edges, the bending moment and the shear force are zero. Taking into account eq (5), these boundary conditions are eqs. (24-27):

$$
\begin{gathered}
\left.\left(D_{y} \frac{d^{2} h_{i j}}{d y^{2}}-v_{y x} D_{x} \lambda_{1 i}^{2} h_{i j}\right)\right|_{y=0}=0 \\
\left.\left(D_{y} \frac{d^{3} h_{i j}}{d y^{3}}-\left(v_{y x} D_{x}+4 D_{x y}\right) \lambda_{1 i}^{2} \frac{d h_{i j}}{d y}\right)\right|_{y=0}=0 \\
\left.\left(D_{y} \frac{d^{2} h_{i j}}{d y^{2}}-v_{y x} D_{x} \lambda_{1 i}^{2} h_{i j}\right)\right|_{y=b}=0 \\
\left.\left(D_{y} \frac{d^{3} h_{i j}}{d y^{3}}-\left(v_{y x} D_{x}+4 D_{x y}\right) \lambda_{1 i}^{2} \frac{d h_{i j}}{d y}\right)\right|_{y=b}=0
\end{gathered}
$$

The application of the boundary conditions from eqs. (24-27) in eq. (23) gives the matrices shown in eq. (28):

$\left[\begin{array}{cccc}0 & \alpha_{i j} & 0 & \theta_{i j} \\ \gamma_{i j} & 0 & \beta_{i j} & 0 \\ \alpha_{i j} \sin r_{2 i j} b & \alpha_{i j} \cos r_{2 i j} b & \theta_{i j} \operatorname{sh} r_{1 j j} b & \theta_{i j} \operatorname{ch} r_{1 i j} b \\ \gamma_{i j} \cos r_{2 i j} b & -\gamma_{i j} \sin r_{2 i j} b & \beta_{i j} \operatorname{ch~} r_{1 i j} b & \beta_{i j} \operatorname{sh~} r_{1 i j} b\end{array}\right]\left\{\begin{array}{c}C_{i j} \\ D_{i j} \\ E_{i j} \\ F_{i j}\end{array}\right\}=\left\{\begin{array}{c}0 \\ 0 \\ 0 \\ 0\end{array}\right\}$

with the intermediate parameters:

$$
\begin{gathered}
\alpha_{i j}=-D_{y} r_{2 i j}^{2}-v_{y x} D_{x} \lambda_{1 i}^{2} \\
\theta_{i j}=D_{y} r_{1 i j}^{2}-v_{y x} D_{x} \lambda_{1 i}^{2} \\
\gamma_{i j}=-D_{y} r_{2 i j}^{3}-\left(v_{y x} D_{x}+4 D_{x y}\right) r_{2 i j} \lambda_{1 i}^{2} \\
\beta_{i j}=D_{y} r_{1 i j}^{3}-\left(v_{y x} D_{x}+4 D_{x y}\right) r_{1 i j} \lambda_{1 i}^{2}
\end{gathered}
$$

For non-trivial solutions of the system (28), the frequency equation is eq. (33): 


$$
\begin{aligned}
& 2 \alpha_{i j} \theta_{i j} \gamma_{i j} \beta_{i j}\left(-1+\cos r_{2 i j} b \cosh r_{1 i j} b\right) \\
& \quad+\left(\theta_{i j}^{2} \gamma_{i j}^{2}-\alpha_{i j}^{2} \beta_{i j}^{2}\right) \sin r_{2 i j} b \sinh r_{1 i j} b=0
\end{aligned}
$$

The parameters $r_{1 i j}$ or $r_{2 i j}$ can be solved from eq. (33), while the natural frequency $\omega_{i j}$ can be obtained from expressions (21) and (22). To determine expressions of the new constants of integration, one simplifies the system (28) by normalizing the first component $C_{i j}$ of the unknown vector by 1 , thereby reducing the problem to 4 equations with 3 unknowns, from which one obtains the expressions for the constants $D_{i j}, E_{i j}$, and $F_{i j}$ eq. (34-36):

$$
\begin{gathered}
D_{i j}=\left(\alpha_{i j} \sin r_{2 i j} b-\frac{\gamma_{i j} \theta_{i j}}{\beta_{i j}} \sinh r_{1 i j} b\right) / \\
\alpha_{i j}\left(\cosh r_{1 i j} b-\cos r_{2 i j} b\right) \\
E_{i j}=-\gamma_{i j} / \beta_{i j} \\
F_{i j}=\left(-\alpha_{i j} \sin r_{2 i j} b+\frac{\gamma_{i j} \theta_{i j}}{\beta_{i j}} \sinh r_{1 i j} b\right) / \\
\left(\theta_{i j} \cosh r_{1 i j} b-\theta_{i j} \cos r_{2 i j} b\right)
\end{gathered}
$$

To calculate the natural frequencies $\omega_{i j}$ of the multispan orthotropic bridge deck, first $\lambda_{I}$ values were calculated. Next the $\lambda_{l i}$ values were determined using eq. (18). Subsequently, the roots $r_{l i j}$ or $r_{2 i j}$ of the frequency eq. (33) were obtained using Mathematica software. Finally, natural frequencies of the multi-span bridge deck $\omega_{i j}$ were calculated by eq. (21-22).

\section{NUMERICAL VALIDATION EXAMPLE}

To validate the method developed in this paper, a numerical example of an Euler-Bernoulli beam with two equal spans with elastic supports is presented (Fig. 4). The beam is of length $l=5 \mathrm{~m}$; width $b=0.05 \mathrm{~m}$; thickness $h=0.05 \mathrm{~m}$; density $\rho=$ $7800 \mathrm{~kg} / \mathrm{m}^{3}$; Poisson's ratio $v=0.3$; and Young's modulus $E_{x}=2.06 \times 10^{11} \mathrm{~N} / \mathrm{m}^{2}$ [6]. In this study, the method of obtaining the frequency parameters $\lambda_{i}$ is based on searching for a non-trivial solution of the determinant of the matrix of the system in eq. (15). This non-linear algebraic equation can be solved in Mathematica software.

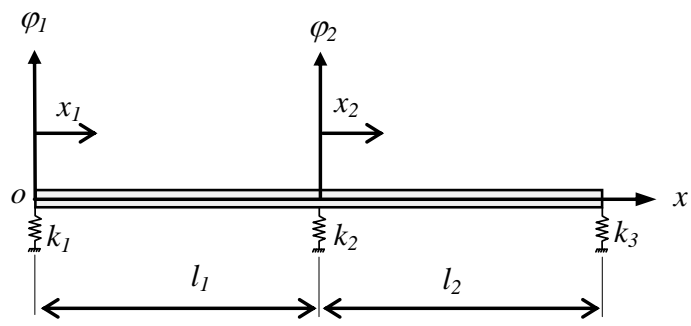

Fig. 4. Beam with two equal spans with elastic point supports

Table 1 presents a comparison between the first four natural frequencies of the beam, calculated by the present method with those presented by Lin and Chang [6], who employed Timoshenko's beam theory to calculate the natural frequencies and mode shapes of a continuous, multi-span beam, simply supported at the ends with flexible intermediate supports, using a hybrid analytical/numerical method. The comparison shows a slight difference between the frequencies. This may be due to the differences between theory and the applied method.

Figure 5 shows the variation of the first four mode shapes of the beam for different values of the intermediate stiffness support $k_{2}$. The same modes were obtained as those in [6]. For Fig. 5 (a) $\left(k_{2}=0\right)$, the mode shapes are identical to those of a beam on two simple supports. When the rigidity of the intermediate support becomes very high $\left(k_{2}=10^{20}\right.$ $\mathrm{N} / \mathrm{m}$ ), the mode shapes are those of a beam on three rigid supports (Fig. 5 (d)). For example, the vertical stiffness of a rubber bearing is calculated to be about $11.55 \times 10^{7} \mathrm{~N} / \mathrm{m}^{2}[15]$.

Table 1. Comparison of calculated natural frequencies of the beam $f_{i}=\lambda_{i}^{2} \sqrt{E_{x} I / \rho A} / 2 \pi$ in $[\mathrm{Hz}]$ with results from the Lin and Chang [6] method shown in parentheses

\begin{tabular}{ccccc} 
Frequency order & $k_{2}=0 \mathrm{~N} / \mathrm{m}^{*}$ & $k_{2}=10^{7} \mathrm{~N} / \mathrm{m}$ & $k_{2}=10^{8} \mathrm{~N} / \mathrm{m}$ & $k_{2}=10^{20} \mathrm{~N} / \mathrm{m}$ \\
\cline { 2 - 4 }$f_{1}$ & 4.661 & 18.643 & 18.643 & 18.643 \\
& $(-----)$ & $(18.738)$ & $(18.738)$ & $(18.614)$ \\
$f_{2}$ & 18.642 & 27.884 & 29.000 & 29.123 \\
& $(-----)$ & $(28.004)$ & $(29.143)$ & $(29.122)$ \\
$f_{3}$ & 41.946 & 74.570 & 74.570 & 74.570 \\
& $(-----)$ & $(74.802)$ & $(74.802)$ & $(74.566)$ \\
$f_{4}$ & 74.570 & 80.251 & 93.052 & $(94.377$ \\
& $(------)$ & $(80.317)$ & $(93.306)$ & $(94.362)$ \\
\hline$k_{l}=k_{3}=10^{20} \mathrm{~N} / \mathrm{m}$ & & &
\end{tabular}

$* k_{1}=k_{3}=10^{20} \mathrm{~N} / \mathrm{m}$. 

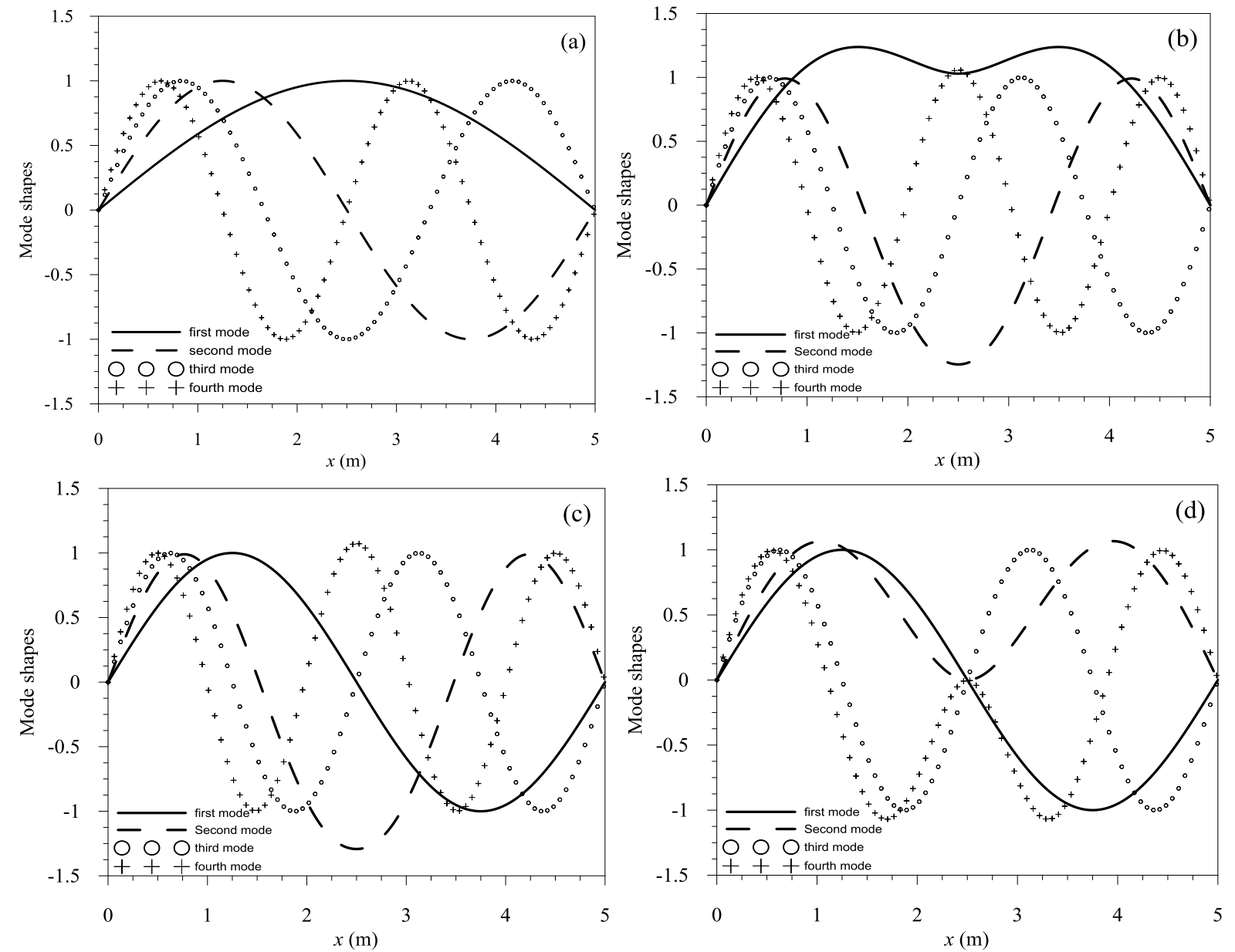

Fig. 5. Variation of the first four mode shapes of the beam for different values of the stiffness of the intermediate support, $k_{1}=k_{3}=10^{20} \mathrm{~N} / \mathrm{m}$, (a) $: k_{2}=0$, (b) $: k_{2}=8 \times 10^{5} \mathrm{~N} / \mathrm{m}$, (c) $: k_{2}=10^{6} \mathrm{~N} / \mathrm{m}$, (d) $: k_{2}=10^{20} \mathrm{~N} / \mathrm{m}$

\section{APPLICATION TO TWO-SPAN, MULTI- GIRDER BRIDGE DECK}

A cross-section of a continuous, two-span, multi-girder bridge is shown in Figs. 6 from [16]. This is used as an example of a concrete isotropic deck slab with five, steel, I-beam girders. The concrete deck slab was of length $l=40 \mathrm{~m}$; width $b=11 \mathrm{~m}$; thickness $h=0.2 \mathrm{~m}$; density $\rho=2300 \mathrm{~kg} / \mathrm{m}^{3}$; Poisson's ratio $v=0.33$, Young's modulus $E=2.1 \times 10^{10}$ $\mathrm{N} / \mathrm{m}^{2}$, and torsional rigidity modulus $G=78.9473$ $\times 10^{8} \mathrm{~N} / \mathrm{m}^{2}$. The distance between two adjacent girders was $b_{l}=2.25 \mathrm{~m}$. The stiffness ratio was $s=$ 0.01255 . The coefficient of equivalent torsional moment of inertia was $\alpha=0.3$. The section characteristics of each I-beam girder were (Fig. 7): web height; $n_{l}=1.13 \mathrm{~m}$; web thickness; $m_{1}=0.175 \mathrm{~m}$; flange width $0.55 \mathrm{~m}$; flange thickness $0.18 \mathrm{~m}$; and quadratic moment $I=0.118 \mathrm{~m}^{4}$.

The equivalent rigidities in the $x$ - and $y$ directions of the orthotropic bridge deck are calculated using the following expressions [16]:

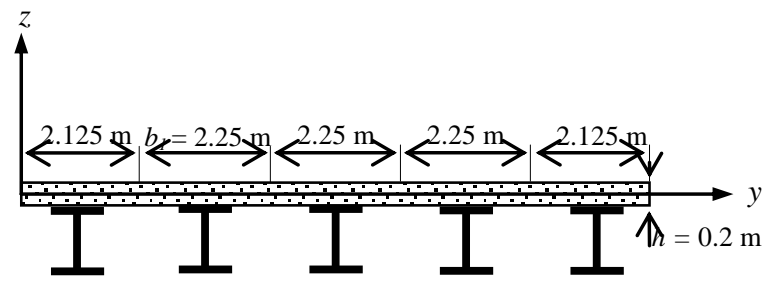

Fig. 6. Cross section of the bridge deck

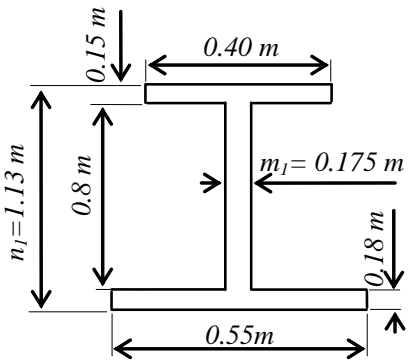

Fig. 7. Steel I-Beam details 


$$
\begin{aligned}
& D_{x}=\frac{E h^{3}}{12\left(1-s v^{2}\right)}+\frac{E I}{b_{1}}=11.153526 \times 10^{8} \mathrm{Nm} \\
& D_{y}=\frac{E h^{3}}{12\left(1-s v^{2}\right)}=1.4019312 \times 10^{7} \mathrm{Nm} \\
& H=v D_{y}+\frac{G h^{3}}{6}+\frac{G m_{1}^{3} n_{1}}{b_{1}} \alpha=2.1527522 \times 10^{7} \mathrm{Nm} \\
& D_{x y}=\left(H-v D_{y}\right) / 2=8.450574 \times 10^{6} \mathrm{Nm}
\end{aligned}
$$

To calculate the natural frequencies $\omega_{i j}$ of the equivalent orthotropic bridge deck, first the values of $\lambda_{i}$ were calculated. Then the solutions of the characteristic equation of the system matrix (15) were solved using Mathematica software. Next, the frequency parameters $\lambda_{l i}$ were obtained using eq. (18). Then the frequency parameters $r_{i j}$ or $r_{2 i j}$ were solved via eq. (33) using Mathematica. Finally, the natural frequencies $\omega_{i j}$ were calculated using eqs. (21-22).

Table 2 shows a comparison between the first ten natural frequencies of the orthotropic bridge deck calculated by this approach and those calculated by ANSYS. The bridge deck was modeled with the finite element type Shell 63 with four nodes and six degrees of freedom per node (Fig. 8). Three mesh density levels were tested: $200 \times 55 ; 240 \times 66$; and $280 \times 77$ elements. The comparison of results shows good agreement for all frequencies (Table 2).

Table 2. Mesh density convergence and comparison of natural frequencies in $(\mathrm{Hz})$ of the bridge deck

\begin{tabular}{cccccc}
\hline & \multicolumn{3}{c}{ ANSYS } & Proposed approach & Error \% \\
\cline { 2 - 4 } & $200 \times 55$ & $240 \times 66$ & $280 \times 77$ & & 0.2 \\
\hline 1 & 3.355 & 3.355 & $\mathbf{3 . 3 5 5}$ & $\mathbf{3 . 3 5 7}$ & 0.0 \\
3 & 3.553 & 3.553 & $\mathbf{3 . 5 5 3}$ & $\mathbf{3 . 5 5 3}$ & 0.2 \\
4 & 5.026 & 5.025 & $\mathbf{5 . 0 2 4}$ & $\mathbf{5 . 0 2 2}$ & 0.2 \\
5 & 5.242 & 5.242 & $\mathbf{5 . 2 4 2}$ & $\mathbf{5 . 2 4 4}$ & 5.0 \\
6 & 5.392 & 5.392 & $\mathbf{5 . 3 9 2}$ & $\mathbf{5 . 4 4 2}$ & 1.2 \\
7 & 6.515 & 6.514 & $\mathbf{6 . 5 1 3}$ & $\mathbf{6 . 5 9 4}$ & 6.7 \\
8 & 9.270 & 9.264 & $\mathbf{9 . 2 6 0}$ & $\mathbf{9 . 2 4 8}$ & 0.4 \\
9 & 10.214 & 10.208 & $\mathbf{1 0 . 2 0 4}$ & $\mathbf{1 0 . 2 6 7}$ & 0.0 \\
\hline
\end{tabular}

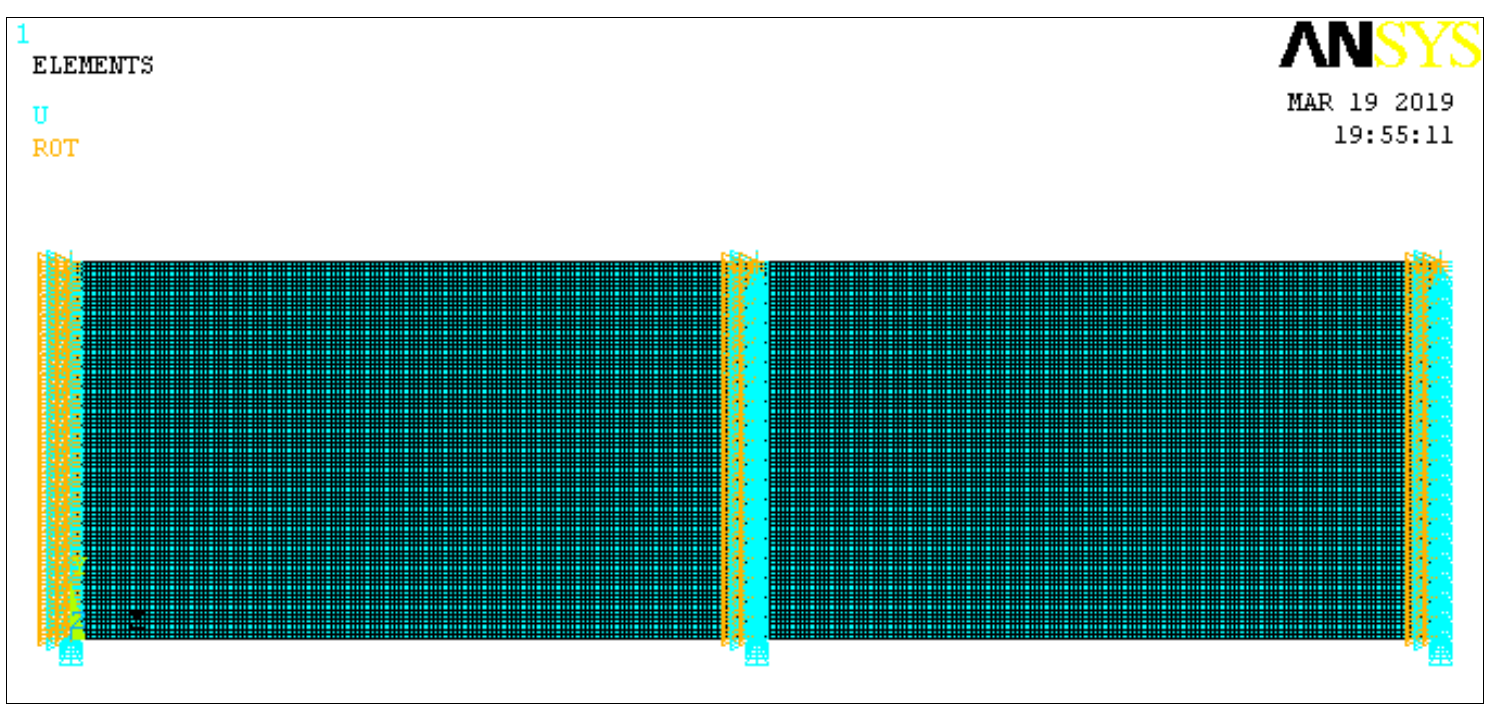

Fig. 8. Finite element model created in ANSYS for evaluating natural frequencies and modes shapes of the orthotropic two-span bridge deck

Figure 9 represents the first six mode shapes of the bridge deck calculated by the proposed approach. Each mode shape is defined by a double index $i j$ according to $x$ and $y$, respectively. The first mode shape of lower frequency, $f_{11}=3.357 \mathrm{~Hz}$ is a bending mode, which does not present any nodal line. All points of the bridge deck vibrate in phase, in this mode. The second frequency mode $\left(f_{12}=\right.$ $3.553 \mathrm{~Hz}$ ) is a torsional mode, which has a nodal line at $y=5.5 \mathrm{~m}$. This is a characteristic of solutions that are obtained as a separable, space variable. Note that the bending modes are of rank $j=1$. The others are torsion modes. Several torsion modes appear before bending modes, because the 
torsional rigidity is lower than bending rigidity. Increasing the order of the torsional mode increases the number of modal lines. Figure 10 shows the

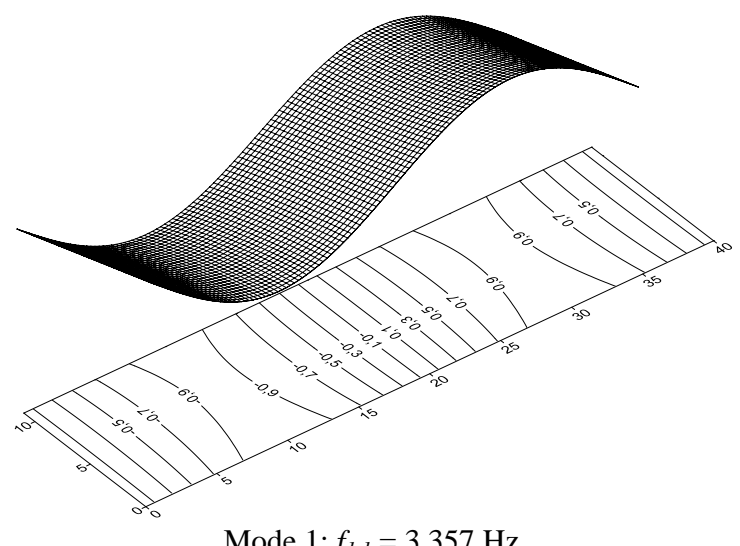

Mode 1: $f_{l, l}=3.357 \mathrm{~Hz}$

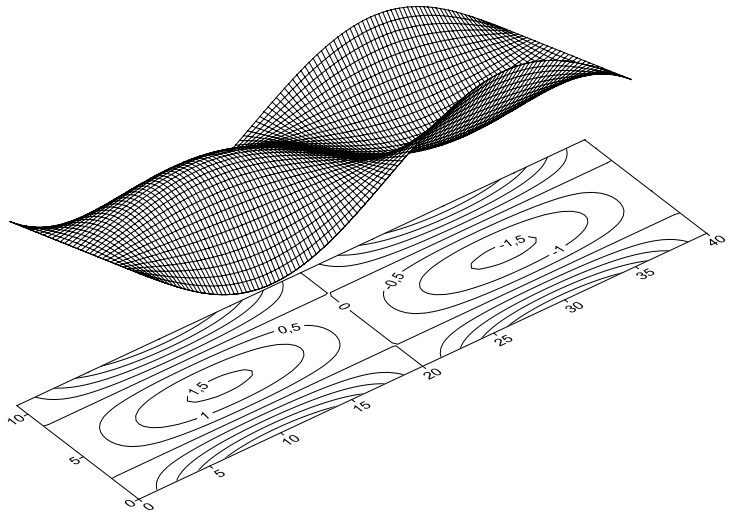

Mode 3: $f_{1,3}=5.022 \mathrm{~Hz}$

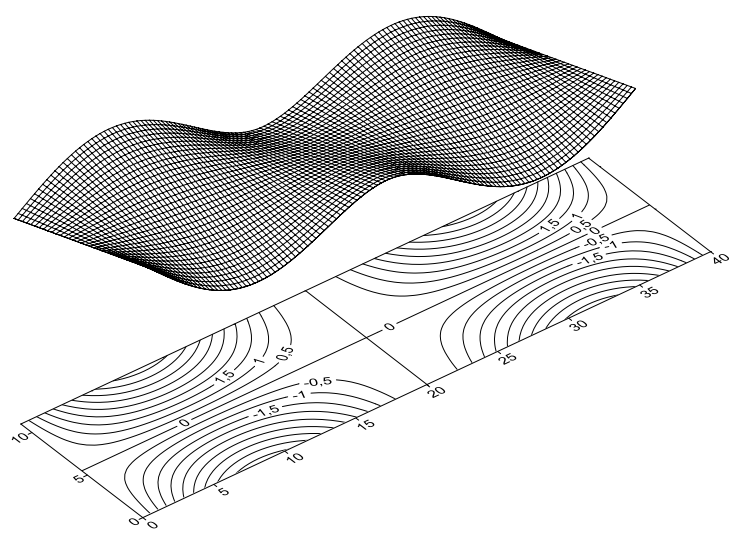

Mode 5: $f_{2,2}=5.442 \mathrm{~Hz}$ first six natural mode shapes of the bridge deck calculated by ANSYS.

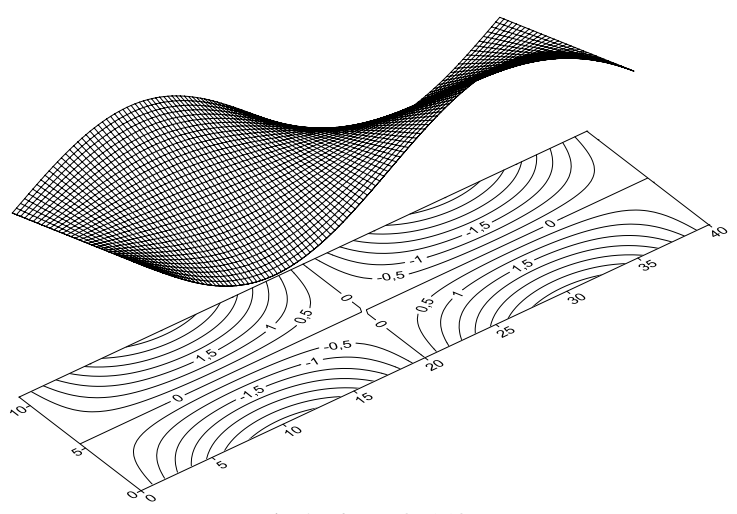

Mode 2: $f_{1,2}=3.553 \mathrm{~Hz}$
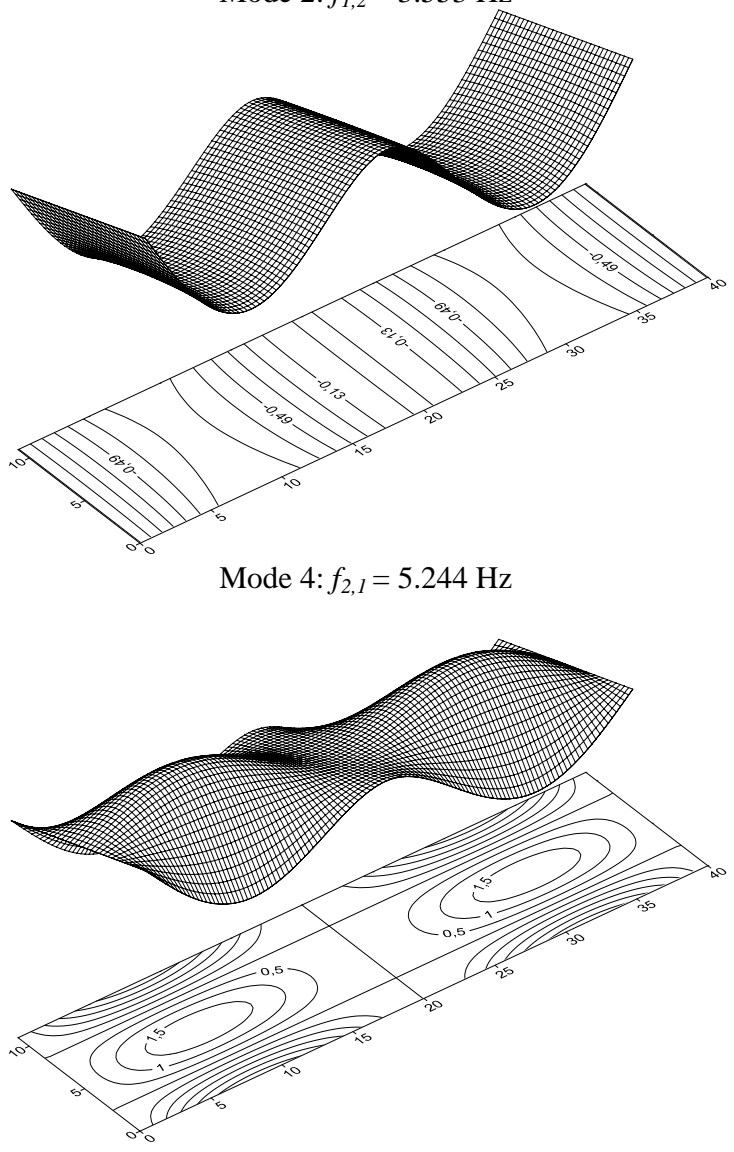

Mode 6: $f_{2,3}=6.594 \mathrm{~Hz}$

Fig. 9. The first six natural mode shapes of the bridge deck, calculated by the proposed approach 

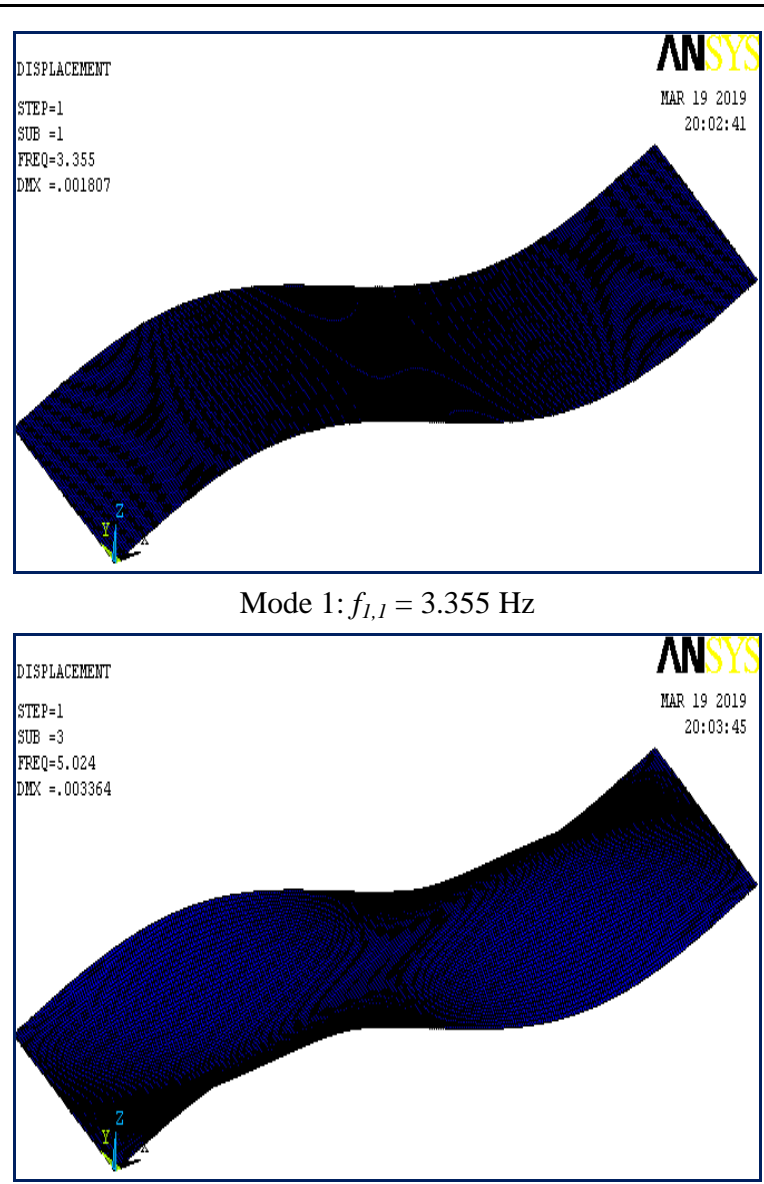

Mode 3: $f_{1,3}=5.024 \mathrm{~Hz}$

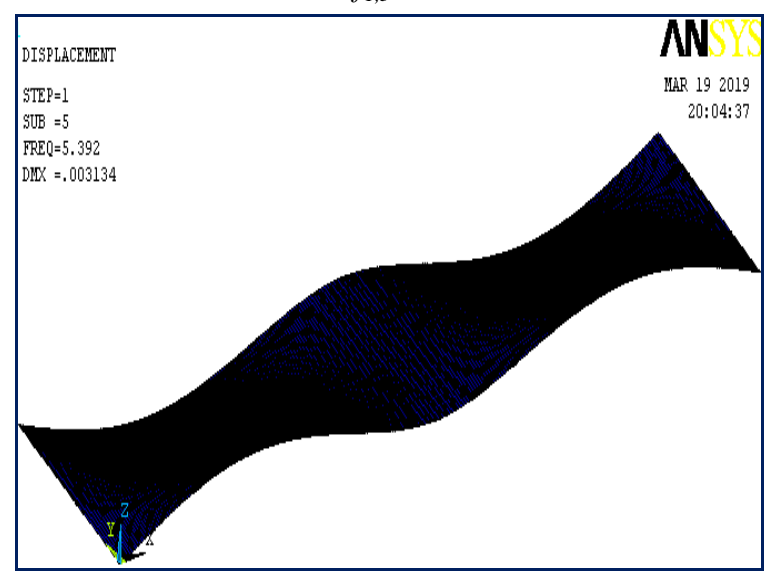

Mode 5: $f_{2,2}=5.392 \mathrm{~Hz}$

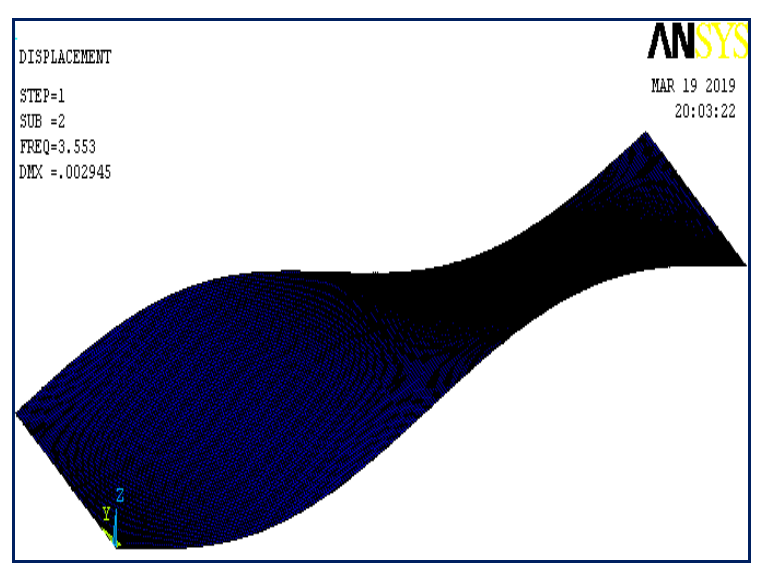

Mode 2: $f_{l, 2}=3.553 \mathrm{~Hz}$

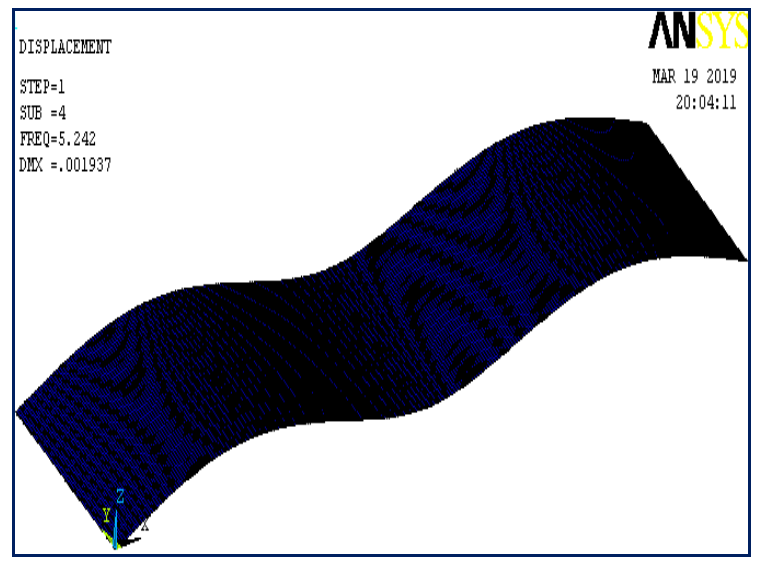

Mode 4: $f_{2,1}=5.242 \mathrm{~Hz}$

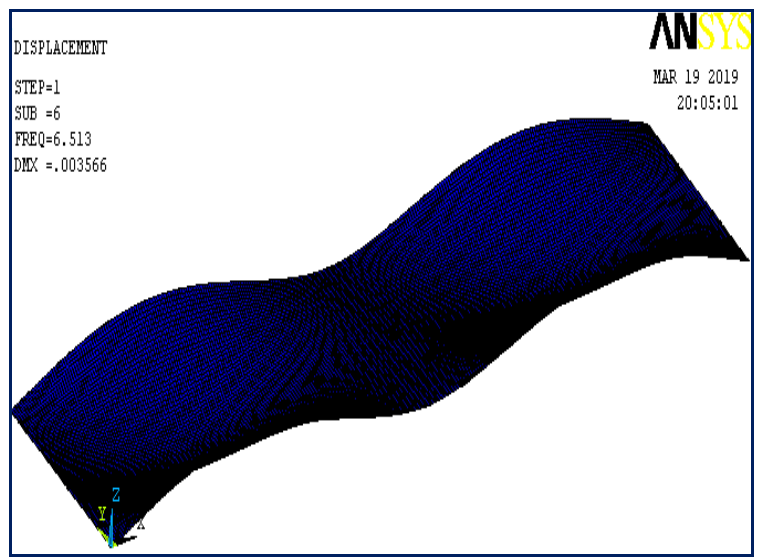

Mode 6: $f_{2,3}=6.513 \mathrm{~Hz}$

Fig. 10. The first six natural mode shapes of the bridge deck, calculated by ANSYS

\section{CONCLUSIONS}

A semi-analytical approach for the calculation of natural frequencies and mode shapes of a bridge deck with rubber bearings was presented. In that, the bridge deck is simplified as a continuous, multispan, orthotropic, rectangular plate with equivalent properties and with linear-elastic supports in one direction. The proposed approach was based on the modal superposition technique combined with intermodal coupling. Two numerical examples were validated upon which the following conclusions were made:
- Results of a two-span Euler-Bernoulli beam were in good agreement with those obtained by Lin and Chang [6];

- When the stiffness of the rubber bearing was small, the effects on the natural frequencies were very large, and the converse is true: low stiffnesses had only small effects on the natural frequencies.

- Results of a two-span, orthotropic, bridge deck were in good agreement with those obtained via an ANSYS analysis.

In reality, the rubber bearings along the $y$-direction are not distributed but, instead, are located beneath 
each girder. This more precise modeling will be the subject of future work.

\section{APPENDIX A}

The elements of vector $\{A\}$ are given by:

$\{A\}=\left\{A_{1}, B_{1}, C_{1}, D_{1}, \ldots, A_{R}, B_{R}, C_{R}, D_{R}\right\}^{T}$ and the elements of matrix $[F]$ are given by:

$f_{11}=E_{x} I \lambda^{3}, f_{12}=-k_{1}, f_{13}=-E_{x} I \lambda^{3}, f_{14}=-k_{1}$

$f_{22}=E_{x} I \lambda^{2}, f_{24}=-E_{x} I \lambda^{2}$

For $r=2,3, \ldots, R$ :

$f_{4(r-2)+3,4(r-2)+1}=E_{x} I \lambda^{3} \cos \beta l_{r-1}+(-1)^{r} k_{r} \sin \lambda l_{r-1}$

$f_{4(r-2)+3,4(r-2)+2}=-E_{x} I \lambda^{3} \sin \beta l_{r-1}+(-1)^{r} k_{r} \cos \lambda l_{r-1}$

$f_{4(r-2)+3,4(r-2)+3}=-E_{x} I \lambda^{3} \operatorname{ch} \lambda l_{r-1}+(-1)^{r} k_{r} \operatorname{sh} \lambda l_{r-1}$

$f_{4(r-2)+3,4(r-2)+4}=-E_{x} I \lambda^{3} \operatorname{sh} \lambda l_{r-1}+(-1)^{r} k_{r} \operatorname{ch} \lambda l_{r-1}$

$f_{4(r-2)+3,4(r-2)+5}=-E_{x} I \lambda^{3}$

$f_{4(r-2)+3,4(r-2)+7}=E_{x} I \lambda^{3}$

$f_{4(r-2)+4,4(r-2)+1}=E_{x} I \lambda^{2} \sin \lambda l_{r-1}$

$f_{4(r-2)+4,4(r-2)+2}=E_{x} I \lambda^{2} \cos \lambda l_{r-1}$

$f_{4(r-2)+4,4(r-2)+3}=-E_{x} I \lambda^{2} \operatorname{sh} \lambda l_{r-1}$

$f_{4(r-2)+4,4(r-2)+4}=-E_{x} I \lambda^{2} \operatorname{ch} \lambda l_{r-1}$

$f_{4(r-2)+4,4(r-2)+6}=-E_{x} I \lambda^{2}$

$f_{4(r-2)+4,4(r-2)+8}=E_{x} I \lambda^{2}$

$f_{4(r-2)+5,4(r-2)+1}=-\sin \lambda l_{r-1}$

$f_{4(r-2)+5,4(r-2)+2}=-\cos \lambda l_{r-1}$

$f_{4(r-2)+5,4(r-2)+3}=-s h \lambda l_{r-1}$

$f_{4(r-2)+5,4(r-2)+4}=-\operatorname{ch} \lambda l_{r-1}$

$f_{4(r-2)+5,4(r-2)+6}=1$

$f_{4(r-2)+5,4(r-2)+8}=1$

$f_{4(r-2)+6,4(r-2)+1}=-\lambda \cos \lambda l_{r-1}$

$f_{4(r-2)+6,4(r-2)+2}=\lambda \sin \lambda l_{r-1}$

$f_{4(r-2)+6,4(i r-2)+3}=-\lambda \operatorname{ch} \lambda l_{r-1}$

$f_{4(r-2)+6,4(r-2)+4}=-\lambda \operatorname{sh} \lambda l_{r-1}$

$f_{4(r-2)+6,4(r-2)+5}=\lambda$

$f_{4(r-2)+6,4(r-2)+7}=\lambda$

$f_{4(R-1)+3,4(R-1)+1}=E_{x} I \lambda^{3} \cos \lambda l_{R}+(-1)^{R+1} k_{R+1} \sin \lambda l_{R}$

$f_{4(R-1)+3,4(R-1)+2}=-E_{x} I \lambda^{3} \sin \lambda l_{R}+(-1)^{R+1} k_{R+1} \cos \lambda l_{R}$

$f_{4(R-1)+3,4(R-1)+3}=-E_{x} I \lambda^{3} \operatorname{ch} \lambda l_{R}+(-1)^{R+1} k_{R+1} \operatorname{sh} \lambda l_{R}$

$f_{4(R-1)+3,4(R-1)+4}=-E_{x} I \beta^{3} \operatorname{sh} \lambda l_{R}+(-1)^{R+1} k_{R+1} \operatorname{ch} \lambda l_{R}$

$f_{4 R, 4(R-1)+1}=E_{x} I \lambda^{2} \sin \lambda l_{R}$

$f_{4(R-1)+3,4(R-1)+2}=E_{x} I \lambda^{2} \cos \lambda l_{R}$

$f_{4(R-1)+3,4(R-1)+3}=-E_{x} I \lambda^{2} \operatorname{sh} \lambda l_{R}$

$f_{4(R-1)+3,4(R-1)+4}=-E_{x} I \lambda^{2} \operatorname{ch} \lambda l_{R}$

and the other coefficients $f_{i j}$ are equal to zero.

\section{REFERENCES}

1. Bakht B, Jaeger LG. Bridge Analysis Simplified. McGraw-Hill, New York, 1985. https://lib.ugent.be/catalog/rug01:000191562

2. Davalos JF, Qiao P, Shan L. Advanced fiberreinforced polymer (FRP) composites for use in civil engineering. Advanced civil infrastructure materials: Science, mechanics and applications ed. Wu HC. New York, EPublishing Inc, 2006; 118-202.

www.woodheadpublishing.com

3. Timoshenko SP, Woinowsky KS. Theory of Plates and Shells, McGraw-Hill Book Company, New York, 1959.

4. Leissa AW. Vibration of plates, Acoustical Society of America, 1993.

5. Zhu XQ, Law SS. Moving load identification on multi-span continuous bridges with elastic bearings. Mechanical Systems and Signal Processing. 2006; 20:1759-1782. https://doi.org/10.1016/j.ymssp.2005.06.004

6. Lin HP, Chang SC. Free vibration analysis of multispan beams with intermediate flexible constraints. Journal of Sound and Vibration. 2005; 281:155-169. https://doi.org/10.1016/j.jsv.2004.01.010

7. Li WL, Zhang X, Du J, Liu Z. An exact series solution for the transverse vibration of rectangular plates with general elastic boundary supports. Journal of Sound and Vibration. 2009; 321: 254-269 https://doi.org/10.1016/j.jsv.2008.09.035

8. Takabatake H, Nagareda Y. A simplified analysis of elastic plate with edge beams. Journal of Computer and Structures. 1999; 70:129-139. https://doi.org/10.1016/S0045-7949(98)00164-3

9. Vinson JR. The behavior of thin walled structures: beams, plates, and shells, Dordrecht Kluwer, 1989.

10. Cheung YK, Zhou D. Vibrations of rectangular plates with elastic intermediate line-supports and edge constraints. Journal of Thin-Walled Structures. 2000; 37:305-331. https://doi.org/10.1016/S0263-8231(00)00015-X

11. Gorman DJ, Garibaldi L. Accurate analytical type solutions for free vibration frequencies and mode shapes of multi-span bridge decks: the span-by-span approach. Journal of Sound and Vibration. 2006; 290: 321-336. https://doi.org/10.1016/j.jsv.2005.03.020

12. Rezaiguia A, Laefer DF. Semi-analytical determination of natural frequencies and mode shapes of multispan bridge decks. Journal of Sound and Vibration. 2009; 328: 291-300. https://doi.org/10.1016/j.jsv.2009.08.007.

13. Rezaiguia A, Fisli Y, Ellagoune S, Laefer DF, Ouelaa N. Extension of semi- analytical approach to determine natural frequencies and mode shapes of a multispan orthotropic bridge deck. Structural Engineering and Mechanics. 2012; 43: 71-87. http://dx.doi.org/10.12989/sem.2012.43.1.071.

14. Kunde MC, Jangid RS. Effects of Pier and Deck Flexibility on the Seismic Response of Isolated Bridges. Journal of Bridge Engineering. 2006; 11(1): 109-121. https://doi.org/10.1061/(asce)10840702(2006)11:1(109)

15. Service d'études techniques des routes et autoroutes, appareils d'appuis en elastomere frette: utilisation sur les ponts, viaducs et structures similaires. Ministere de l'ecologie du developpement et de 
l'amenagement durable, republique française. 2007. https://www.decitre.fr/livres/appareil-d-appui-enelastomere-frette-5552000544343.html

16. Zhu XQ, Law SS. Dynamic behavior of orthotropic rectangular plate under moving loads. Journal of Engineering Mechanics. 2003; 129(1): 79-87. https://doi.org/10.1061/(ASCE)07339399(2003)129:1(79)

Received 2020-04-30

Accepted 2021-01-05

Available online 2021-01-08

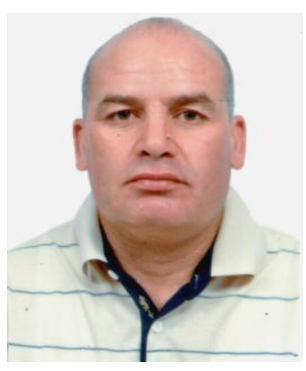

Imed FARAH, is a PhD student in Applied Mechanics of New Materials Laboratory at the University of 8 may 1945Guelma, Algeria. Areas of interest: vibrations and modelling.

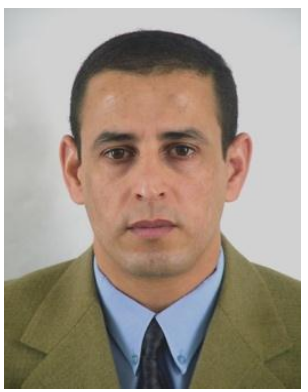

Abdelouahab REZAIGUIA, received his $\mathrm{PhD}$ degree in Mechanical Engineering in 2008 from Annaba University. $\mathrm{He}$ is a Professor in the Department of Mechanical Engineering, University of 8 may 1945-Guelma, Algeria. He is a member of Applied Mechanics of New Materials Laboratory. Research topics: Dynamic behaviour of structures under moving loads, Rotordynamics.

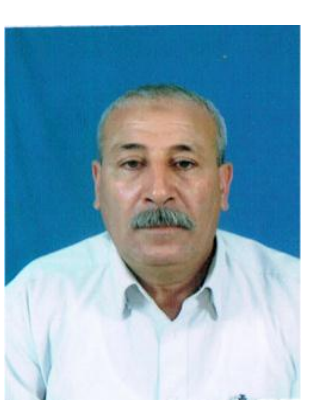

Ahcene MOUASSA, received his $\mathrm{PhD}$ degree in Mechanical Engineering in 2011 from University of 8 may 1945Guelma. He is a member of Mechanic and Structures Laboratory. $\mathrm{He}$ works at the Department of Mechanical Engineering at the same University. Research topics: Hydrodynamic and elastohydrodynamic lubrication of journal bearings, structural dynamics.

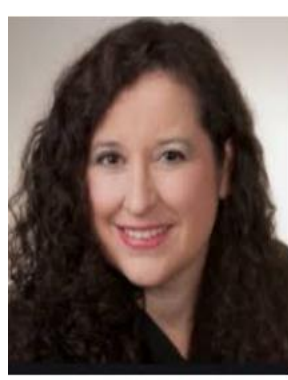

Debra LAEFR, received her $\mathrm{PhD}$ degree in civil engineering in 2001 from the University of Illinois Urbana-Champaign. She is a Full Professor in the Department of Civil and Urban Engineering at New York University and leads the Urban Modeling Group at the Center for Urban Science and Progress.

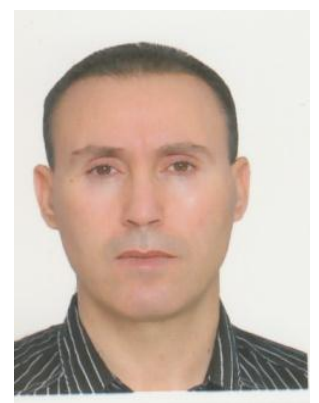

Salah GUENFOUD, received his $\mathrm{PhD}$ degree in Structural Mechanics in 2001 from the Belarusian National Technical University. He is a Professor in the Department of Mechanical Engineering in 8 may 1945 University-Guelma, Algeria. He is a member of Applied Mechanics of New Materials Laboratory. Research topics: modelling of the structures with any boundary conditions in static and dynamic, modelling of structures of composite materials, inverse problems. 